\title{
Tribological Behaviour of Coated Carbide Tools during Turning of Steels with Improved Machinability
}

\author{
Amar Sebhi $1{ }^{1}{ }^{*}$ - Hocine Osmani 1 - Joel Rech ${ }^{2}$ \\ ${ }^{1}$ Optics and Precision Mechanics Institute, University of Ferhat Abbes, Setif, Algeria \\ 2 Laboratory LTDS National School of Engineering, Saint Etienne, France
}

When competing with the industrial productivity, respecting the general rules of work and ecology of the environment system by avoiding various types of lubricating liquid, solid or any other form of machining, research is directed towards the steels with improved machinability and coating cutting tools.

In order to best understand this, new and modern study parameters related to the cutting phenomenon have to be used, so it will be closer to the tribology of contact tool/chip/workpiece. In this context, the interaction of tribological of pairs of materials with improved machinability steels / coated carbide tools and the relationship between the friction coefficient, cutting speed, tool wear and surface quality will be studied. In this case a tribometer designed to identify the friction coefficient in difficult cutting conditions is used. The following steels (42CrMo4, 27MnCr5), TiN, AlTiN coated carbide tools have been used in the experimental work.

Keywords: tribology, coated tool, wear, roughness, friction coefficient, specific cutting force

\section{INTRODUCTION}

In metal cutting operations, the turning process, which is the object of this study represents $33 \%$ of this domain [1]. There is a constant search for new techniques to improve the productivity while preserving the environment from harmful waste. The rational implementation of such techniques passes indeed by a deep knowledge of the cutting process and the control of different parameters.

Lubricants are not desirable as a solution to minimise the heating of the tool / work piece; because of the permanent and progressive conditions of ecologists [2] and [3]; in some way it must be enviromentally adapted.

Looking for a better productivity of metal cutting is therefore a major concern of researchers. Steels with improved machinability; various coatings of cutting tools, machining at high speeds, the study of tribological interface tool-chip-workpiece, constantly improve product quality and productivity. The main purpose is to participate in the development of new ways of machining or new techniques of programming and control to improve productivity. Depending on the machining conditions, the wear process of cutting tools can affect one, two or all active faces of the tool [4] and [5]. This can lead to inaccurate tolerances of the machined parts. The wear of cutting tools can occur through erosion, abrasion, adhesion and diffusion [6] and [7]. Such problems, essentially of tribological, nature vary considerably from one family to another family of steels. Materials characterization is essential in developing new products of steels [8] and [9]. Therefore, it is necessary to develop an accurate cutting simulation to identify optimal conditions in terms of cutting tool materials, tool geometry and coating in order to support the improvement of productivity and machining operations [10] and [11]. When the cutting speeds are higher than 280 $\mathrm{m} / \mathrm{min}$ and contact pressures in GPa are also higher, this will lead the designers of machine tools to verify their calculations on the basis of important constraints. The system is known as the pin-on-disk system, which is unfortunately not able to simulate the contact conditions in cutting, since the conditions (temperature, pressure) are not real [12] and [13]. The phenomena occurring at the interface of the tool-chip (secondary shear zone) and at the interface of the toolworkpiece may be identified by the new tribometer in order to achieve a precise modeling using finite element methods [9].

In order to characterize some materials developed by Ascométal within the LTDS, and particularly the friction coefficient between cutting tool and machined metal, the exchange of heat flow, tool wear, quality of machined surface, series of tests on an axial tribometer have been carried out (Fig 1). The tribological phenomena at the interface tool / machined surface / chip are very complex to model and yet they are the key behavior of the tool, including its resistance to wear.

The present work lays out experimental results on the TiN and AlTiN wear behaviour when applying an agressive machining on $42 \mathrm{CrMo} 4$ and $27 \mathrm{MnCr} 5$ steels. In addition, surface quality degradation, cutting force and heat flow evolution are related to the tool wear. 
In fact, all the computer codes treat this problem as a constant Coulomb friction, while the occurrance of intense adhesion phenomena as well as chemical reactions and diffusion processes can be noticed [9]. Coated carbide tools have proved their performance in relation to the uncoated tools [14] and [15]. It is of importance to optimize the cutting parameters, such as sliding speed, the feed per revolution and the lifetime of the tool in order to ensure proper control of machining. A new rule concerning the adherence of friction and sliding speed in machining is on prospect [16] to [18].

\section{EXPERIMENTAL PROCEDURE}

The tests were performed in the Laboratory of Tribology and System Dynamics (LTDS) Saint Etienne, France, using round bars made of $42 \mathrm{CrMo} 4$ and $27 \mathrm{MnCr} 5$ steels with $80 \mathrm{~mm}$ diameter and $600 \mathrm{~mm}$ length with improved machinability. The longitudinal turning and tribological cutting operations (in orthogonal cutting), were performed on conventional lathe (Gazeneuve). The chemical composition of the material to be tested is given in Table 1 .

The machine being used is Gazneuve lathe (Figs. 1 and 2), equipped with KISTLER 9257B standard dynamometer with the objective to measure in real time the three force components along $x, y, z$.

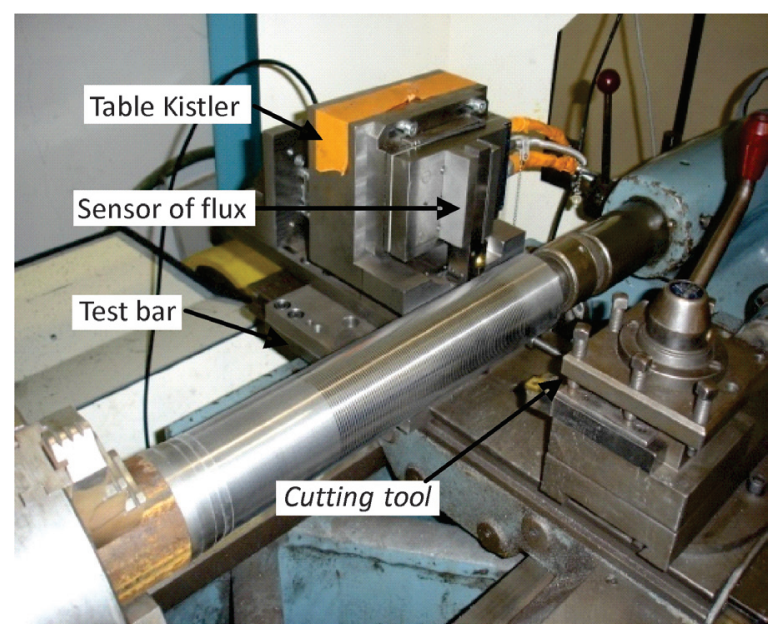

Fig. 1. Cutting test and machining on an instrumented Gazeneuve lathe installation

An interface for acquisition of heat flow is directly connected to the pin holder whose principle is based on thermistor transducers (Fig. 2).

The tests have been carried out in a dry environment without lubrication. Wear has been investigated taking into consideration the following

parameters: feed rate, $f, 0.8 \mathrm{~mm} / \mathrm{rev}$ for cutting and $2 \mathrm{~mm} / \mathrm{rev}$ for scratching, cut depth, $a_{p}$ of $2 \mathrm{~mm}$ and cutting speed $V_{c}$ between 20 and $180 \mathrm{~m} / \mathrm{min}$.

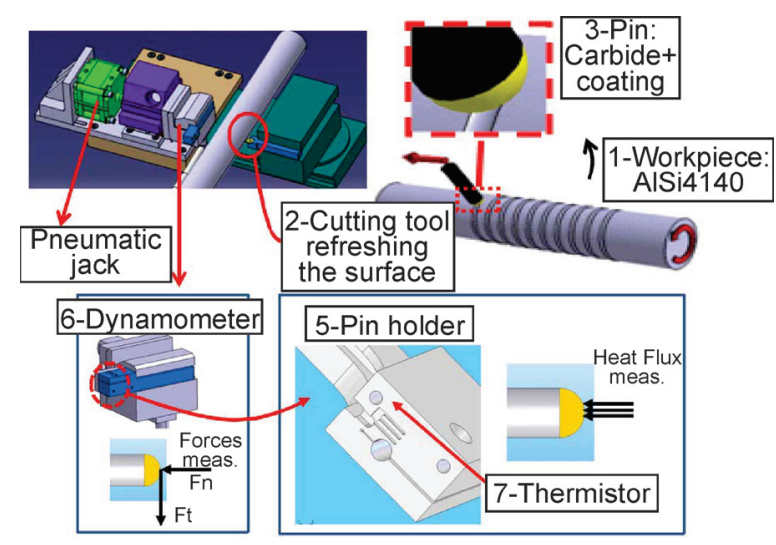

Fig. 2. Measure principles on a tribometer intended to acquire the efforts and the heat flow

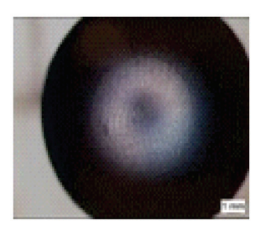

AITiN

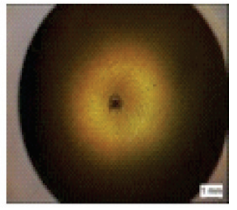

TiN

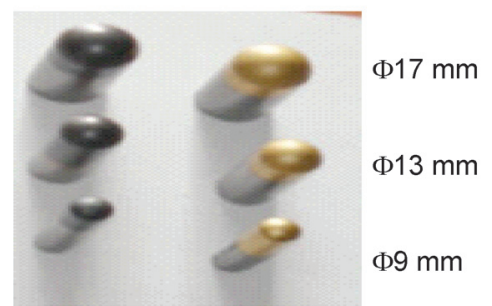

Fig. 3. The different colors of pins coated and their diameter $\mathrm{F} 17,13$ and $9 \mathrm{~mm}$

Roughness measurements have been obtained by means of a surftest 301 roughness meter.

Table 1. Chemical composition of the material test in weight $\%$

\begin{tabular}{lcccccccc}
\hline $\begin{array}{l}\text { Material } \\
\text { designation }\end{array}$ & $\mathrm{Fe}$ & $\mathrm{C}$ & $\mathrm{Si}$ & $\mathrm{Mn}$ & $\mathrm{Cr}$ & $\mathrm{Mo}$ & $\mathrm{P}$ & $\mathrm{S}$ \\
\hline 42CrM04 & 96.7 & 0.39 & 0.28 & 0.89 & 1.08 & 0.27 & 0.01 & 0.018 \\
\hline $27 \mathrm{MnCr5}$ & 96.5 & 0.26 & 0.23 & 1.2 & 1.1 & 0.05 & 0.01 & 0.03 \\
\hline
\end{tabular}

After each test, the work piece is dismantled in order to explore the striations and different measures, then reassembled the bar for the next test after turning with a carbide tool and then polished with a very fine sandpaper to get a better surface possible for the next test. Machining parameters are given after each result. 
The carbide coated pins, AlTiN, TiN (Fig. 3), with spherical heads and of different diameter 9, 13 and 17 $\mathrm{mm}$ (Fig. 3), used for stripping have a finite surface by polishing them on a machining center using 5 axes with the aim to get a better possible surface quality. Stock removal tool with a removable patch made of carbide coated surface is used to regenerate the wear.

In order to measure the wear resistance, a device based on the variation of the width and the depth of the scratch (flank wear or crater) is adapted to an optical microscope.

\section{RESULTS AND DISCUSSION}

\subsection{Effect of Cutting Speed on the Coefficient of Friction}

The tribological cutting tests on $42 \mathrm{CrMo} 4$ steel with a hardness (HB 290), using TiN and TiAlN pins of diameter 13 obtained by PVD at different speeds, are shown in (Fig. 4). The test bench can generate furrows along the specimen as shown in (Fig. 2).

It has been noticed that the coefficient of friction decreases considerably when increasing the cutting speed. For the TiN pin, the fall is precipitous until a speed of $60 \mathrm{~m} / \mathrm{min}$ is achieved. The AlTiN pin behaves otherwise by falling steadily until 0.23 to a speed of $180 \mathrm{~m} / \mathrm{min}$. Here, the apparent friction coefficient which is calculated through the measure of the effort using the following equation, should be mentioned:

$$
\mu_{\text {macr }}=F_{T} / F_{N} .
$$

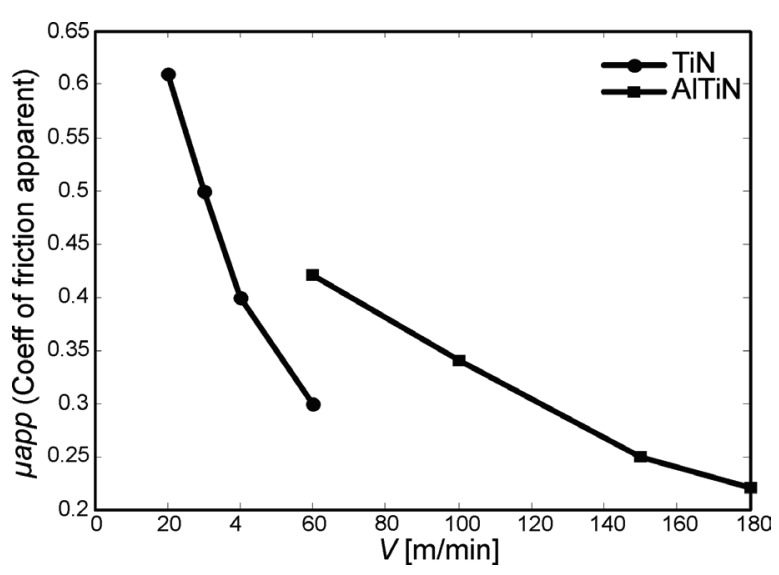

Fig. 4. Effect of cutting speed on the coefficient of friction

\subsection{The Effect of Normal Stress on the Heat Flow Transmitted to the Pin}

Fig. 5 shows the heat flow evolution transmitted to the pin. Beyond this value, the slope of the flow growth decreases. In fact, and during the contact pin / work piece at a cutting speed of $120 \mathrm{~m} / \mathrm{min}$, intense heat is created and increase steadily as the normal stress increases. At $600 \mathrm{~N}$ value, the transmitted heat flow to the pin becomes regular and linear.

A rapid growth of the heat flow transmission between 200 and $400 \mathrm{~N}$ can be noticed.

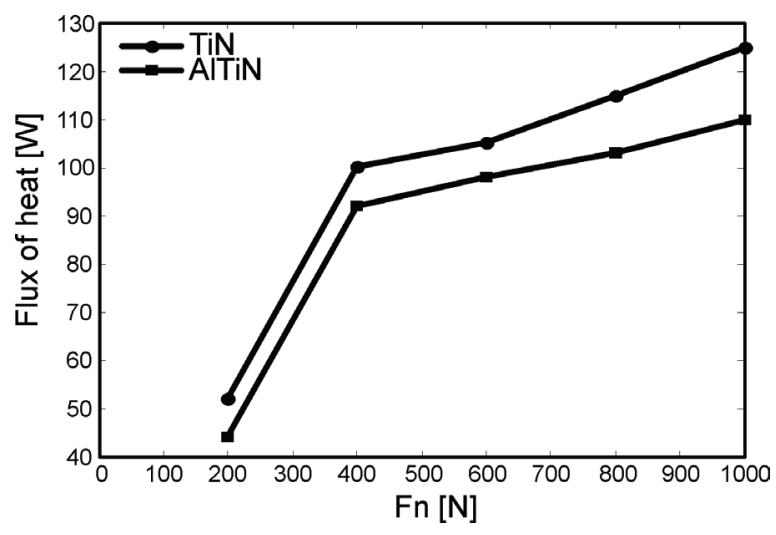

Fig. 5. Effect of the normal force on the heat flow transmitted to the pin

It is noticed that at $400 \mathrm{~N}$, the appearance of the heat flow changes significantly. This can be explained by the effect of heat diffusion across the pin.

\subsection{Wear as a Function of Time}

During longitudinal turning and in order to prepare the next test, it is of importance to measure the wear of TiN coated carbide inserts as shown in Fig. 1 and meanwhile searching the interaction between the two forms of wear (flank $V_{B}$ and crater $K_{T}$ ) as function of time of cutting. It can be noticed from Fig. 6 that the curves are continuous.

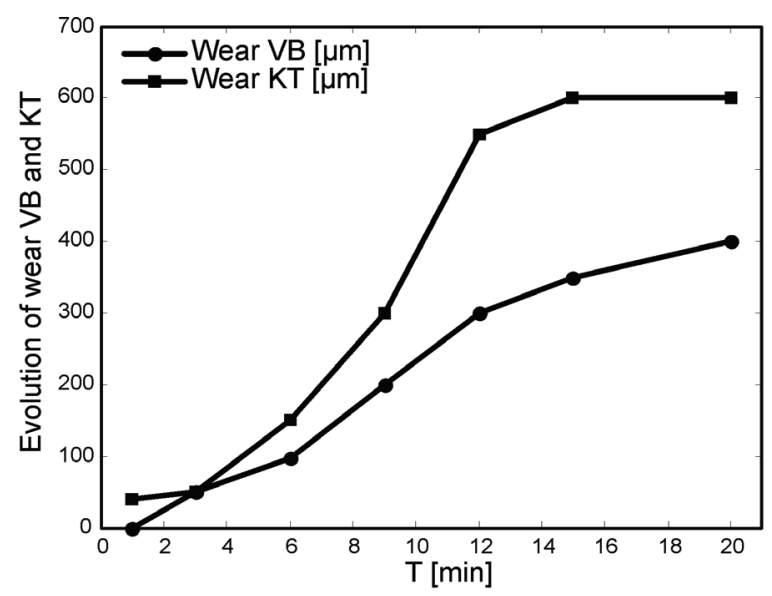

Fig. 6. Evolution of wear VB and KT with time for the cutting speed $150 \mathrm{~m} / \mathrm{min}$ 
After a rapid wear at the beginning of the test, the shape of frontal wear $V_{B}$ becomes almost linear. Beyond $0.4 \mathrm{~mm}$ the crater wear rate $\left(K_{T}\right)$ increases quickly. For finish operations (following ISO standard ISO 3685-1977 (F) $0.3 \mathrm{~mm}$ wear finish and $0.6 \mathrm{~mm}$ for draft), which is the case, the flank wear $V_{B}$ which is more representative it is then taken into account.

Both wear $V_{B}$ and $K_{T}$ combined lead to the collapse of the insert.

\subsection{Evolution of the Roughness as a Function of Wear}

As can be seen from the three curves in Fig.7 and at different speeds, it can be noticed that the surface finish obtained (work piece) with unworn tools is almost regular (near $0.4 \mu \mathrm{m}$ ). Gradual damage of the surfaces corresponding to the increased wear can also be noticed. In the case where $V_{B}=300 \mu \mathrm{m}$ is taken as a wear criterion, a significant degradation of the surface which results in an increase in the value of $R a$ can be noticed In fact, for fixed upper limit of roughness to $R a=0.6 \mu \mathrm{m}$, it has been observed that the lifetime of the plate is significantly reached.

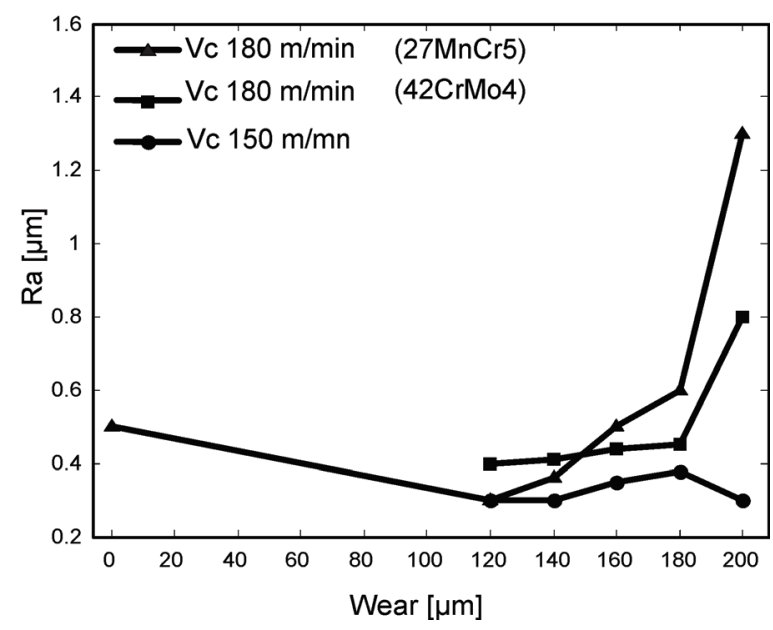

Fig. 7. Roughness Ra as a function of wear $V_{B}$

\subsection{Observation of Worn Pieces}

Observation of friction pins allows us to reinforce the assumptions made when interpreting friction measurements. It particularly expresses the respective behavior of materials towards adhesion, diffusion or other tribological phenomena of the contact couple materials (workpiece-pin).

At the end of the experimental test, the optical and electronic micrographes of the pin show that the damaged surface is very torn. This is due to severe adhesive wear. This result is confirmed by the adhesion of iron deposits detached from the piece (Fig. 8)
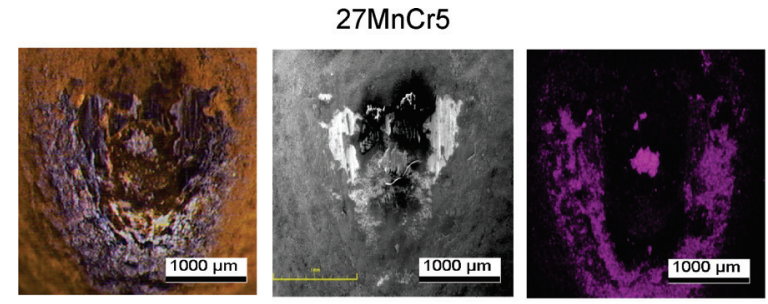

42CrMO4
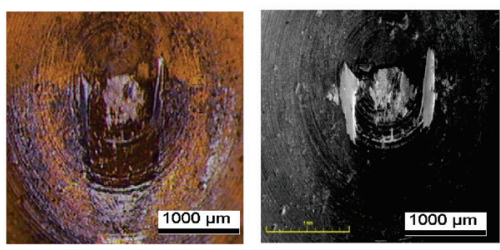

microscope

SEM

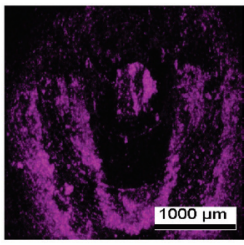

Analysis EDS Iron element

Fig. 8. Observation and analysis of the wear of the pins to after 30 min of different friction types of observation $V_{c}=80 \mathrm{~m} / \mathrm{min}, f=2 \mathrm{~mm} / \mathrm{rev}$

Three different types of observation have been performed: on a binocular microscope, on a scanning electron microscope (SEM), and finally an EDS (Energy-dispersive X-ray spectroscopy) chemical analysis of elements found on the surface of the pins. The SEM technique is based on the principle of electron-matter interactions. It is therefore sufficient to scan the electron beam over its entire surface. Moreover, the SEM used in the laboratory can also analyze the spectrum of X- ray by dispersive energy using a microprobe EDS or EDX (energy dispersive $\mathrm{X}$-ray spectroscopy). The analyses of structure and composition are performed in a single step, which has the advantage of a fast data acquisition. The observation of pins with a binocular microscope gives little information about their wear. It is quite difficult to distinguish between areas where the coating has been damaged and areas that have been coated by the adhesion of $27 \mathrm{MnCr} 5$. The SEM observations are made after being cleaned pins with ultrasound and acetone. This partly reduces steel deposits on the surface, allowing greater precision of analysis. The resulting images show the existence of two types of alteration of the coating depending on the type of the material used. The pin being rubbed against $27 \mathrm{MnCr} 5$ rods shows an adhesive wear, with a tearing of two plates at the ends of the contact zone. The center of this same zone is protected by adhesive deposits which are shown in black. For the $42 \mathrm{CrMo} 4$ material pin, there is a clear presence of two trenches left by 
the edges of the grooves. Here one can talk about an abrasive wear, since such marks are parallel to the direction of motion. The existence of these two types of wear which are specific to each material is common in the tribological behavior when a couple of materials is used. The adhesive regime often leads to sudden changes of wear which can be due to simple modifications of friction parameters.

EDS analyses do not provide further information. Only deposits of the Iron element in the case of $42 \mathrm{CrMo} 4$ confirmed by the density of the alloy, the net propensity to adhere more firmly to the friction surface of the pins compared to $27 \mathrm{MnCr} 5$ alloy.

\subsection{Observation of Track Turning}

It is well noticed the existence of striations which are parallel to the pin sliding direction, which qualify this kind of wear as soft abrasion wear. This observation seems consistent with the difference between the two materials in contact.

In addition, there is a discharge of matter towards the edges of tracks (groove), a sign of ploughing, due to the steel ductility. The observation of the pin at the end of the test very clearly shows a non-uniform wear of the head of the pin.

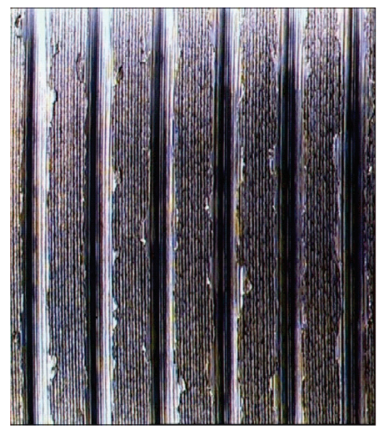

Pin $\varnothing 13 \mathrm{~mm}$

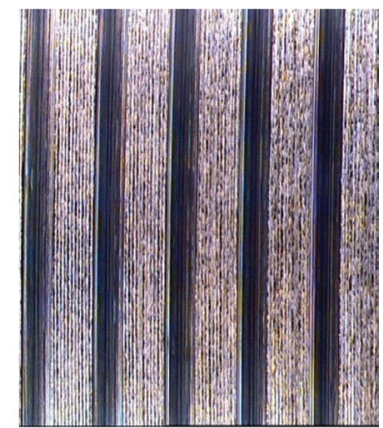

Pin $\varnothing 17 \mathrm{~mm}$
Fig. 9. Comparison of scratches obtained after scratching using pins $\emptyset 13 \mathrm{~mm}$ and diameters $\emptyset 17 \mathrm{~mm}$; 42CrMo4 - magnification $\times 1-V_{c}=80 \mathrm{~m} / \mathrm{min}$

The widths of scratches observed on $27 \mathrm{MnCr} 5$ bars remain relatively constant (Fig. 9), during testing. Only those left by the pins in the bars of standard material, increase furtively after the first twenty minutes of friction. This seems to confirm the destabilizing of the recorded coefficients of friction. Therefore, there is a slight difference in behavior on the friction with time between the two alloys. The scratches left in the $27 \mathrm{MnCr} 5$ alloy are in fact much larger than those left on of $42 \mathrm{CrMo} 4$ alloy (about
$1.8 \mathrm{~mm}$ ) showing a more pronounced wear of the pin associated with the $27 \mathrm{MnCr} 5$ alloy (about $1.25 \mathrm{~mm}$ ).

After each friction testing, the used piece is removed from the lathe to take measurements of scratch widths left by the pin on it.

Measurements are performed in the middle of the specimen (and therefore at the middle of the experiment). These data will enable us to assess the contact local pressure, to express the densities flow, and to evaluate the speed impact on the sliding conditions of the pin.

\section{CONCLUSION}

The main conclusions are:

1. It has been noted that the coefficient of friction between $\mathrm{TiN}$ and $42 \mathrm{CrMo} 4$ alloy is better than that between AITiN and $42 \mathrm{CrMo} 4$ alloy at a speed of $60 \mathrm{~m} / \mathrm{min}$.

2. The heat flow transmitted to the TiN pin at high pressure (for an applied force greater than $400 \mathrm{~N}$ ) is more important for TiN pin than for AlTiN pin.

3. During the tests, it could be noticed that the flank wear VB and crater wear KT become more and more important, especially at high cutting speeds (more than $150 \mathrm{~m} / \mathrm{min}$ ). They often result in the breakdown of the tool nose and then they result in the inaccuracy of the tolerances of the workpiece.

4. The surface quality is better for low rate of wear VB (lower than $200 \mathrm{~mm}$ ); beyond this value the roughness $\mathrm{Ra}$ increases as function of the cutting speed Vc.

5. The system set-up has showed that the apparent friction coefficient decreases considerably by increasing the cutting speed. This model also showed the important effect of temperature on contact pressure.

The most distinguished wear phenomenon in this case is the abrasive wear which appears by the side of grooving tools. Abrasion is caused by hard particles existing in the material being machined. In this case, particular attention should be given to work pieces dimensioning, tolerances, surface quality and machining precision which could be significantly affected. The graphs found in this work can serve as abacus for selecting the optimum cutting speed, the interpolation surface quality product and service life of the tool optimum.

\section{ACKNOWLEDGMENTS}

This work was started at the Laboratory of Tribology and System Dynamics (LTDS) Saint Etienne France, 
and then completed at the Unit Industrial Equipment Maintenance (IEM) Group SONALGAZ Algeria. The authors express their gratitude to the Ministry of Higher Education of Algeria and all the people who have collaborated directly or indirectly to this work.

\section{REFERENCES}

[1] Jasppers, S.P.F.C., Dautzenbergb, J.H. (2002). Material behaviour in conditions similar to metal cutting: flowstress in the primary shear zone. Process and Technology, vol. 122, no. 2-3, p. 322-330, DOI:10.1016/S0924-0136(01)01228-6.

[2] Osel, T. (2006). The influence of friction models on finite element simulations of machining. International Journal of Machine Tools and Manufacture, vol. 46, p. 518-530, DOI:10.1016/j.ijmachtools.2005.07.001.

[3] Ryckelynck, D., Meiller, M. (2002). Friction modeling of tool workpiece contact for the finite element simulation of cutting process. Mechanics and Industries, vol. 3, p. 323-332, DOI:10.1016/S12962139(02)01172-7.

[4] Galoppia, G.D.S., Stipkovic Filhoa, M., Batalhaa, G.F. (2006). Hard turning of tempered DIN 100Cr6 steel with coated and no coated CBN inserts. Journal of Materials Processing Technology, vol. 179, no. 1-3, p. 146-153, DOI:10.1016/j.jmatprotec.2006.03.067.

[5] Belhadi, S., Mabrouki, T., Rigal, J.F., Boulanouar, L. (2005). Experimental and numerical study of chip formation during straight turning of hardened AISI 4340 Steel. Proceedings of the Institution of Mechanical Engineers, Part B: Journal of Engineering Manufacture, vol. 219, no. 7, p. 515-524, DOI:10.1243/095440505X32445.

[6] Bouchelaghem, H., Yallesse, M.A., Amirat, A., Belhadi, S. (2007). Wear behaviour of CBN tool when turning hardened AISI D3 steel. Mechanika, vol. 65, no. 3, p. 57-65.

[7] Farhat, Z.N. (2003). Wear mechanism of CBN cutting tool during high-speed machining of mold steel. Materials Science and Engineering: A, vol. 361, no. 1-2, p. 100-110, DOI:10.1016/S0921-5093(03)005033.

[8] Qi, H.S., Mills, B. (1996). On the formation mechanism of adherent layers on a cutting tool. Wear, vol. 198, no. 1-2, p. 192-196, DOI:10.1016/0043-1648(96)80023-8.

[9] Zemzemi, F., Bensalem, W., Rech, J., Dogui1, A., Kapsa, P. (2007). New tribometer designed for the characterization of the friction properties at the tool/ chip/workpiece interfaces in machining. Tribotest, vol. 14, p. 11-25, DOI:10.1002/tt.50.

[10] Chaari, R., Abdennadher, M., Louati, J., Haddar, M. (2011). Modelling of the 3D machining geometric defects accounting for workpiece vibratory behaviour. International Journal of Simulation Modelling, vol. 10, no. 2, p. 66-77, DOI:10.2507/IJSIMM10(2)2.173.

[11] Senthil Kumar, A., Raja Durai, A., Sornakumar, T. (2006). Wear behavior of alumina based ceramique cutting tools on machining steels. Tribology International, vol. 39, no. 3, p. 191-197, DOI:10.1016/j. triboint.2005.01.021.

[12] Appa Rao, G., Srinivas, M., Sarma, D.S.(2004). Effect of thermomecanichal working on the microstructure and mechanical properties of hot isostatically pressed superalloy inconel 718. Materials Science and Engineering, vol. 383, no. 2, p. 201-212, DOI:10.1016/j.msea.2004.05.062.

[13] Grzesik, W., Nieslony, P. (2004). Prediction of friction and heat flow in machining incorporating thermophysical properties of the coating-chip interface. Wear, vol. 256, no. 1-2, p. 108-117, DOI:10.1016/ S0043-1648(03)00390-9.

[14] Gautier, L. (2004). Study of the mechanisms of damage carbide tools WC-Co for the characterization of the tool-chip interface. Application to dry machining of aluminum alloy Aerospace AA2024 T351, PhD Thesis, Engineer of National Engineering School of Metz, University of Paris, Paris.

[15] Ruppi, S., Högrelius, B., Huhtiranta, M. (1998). Wear characteristics of TiC, $\mathrm{Ti}(\mathrm{C}, \mathrm{N})$, TiN and A1203 coatings in the turning of conventional and Ca-treated steels. International Journal of Refractory Metals \& Hard Materials, vol. 16, no. 4-6, p. 353-368, DOI:10.1016/ S0263-4368(98)00039-0.

[16] Bahi, S., Nouari, M., Moufki A., El Mansouri, M., Molinari, A. (2011). A new friction law for sticking and sliding contacts in machining. Tribology International, vol. 44 , no. $7-8$, p. 764-771, DOI:10.1016/j.triboint. 2011.01.007.

[17] Çiçek, A., Kıvak, T., Samtaş, G. (2011). Application of taguchi method for surface roughness and roundness error in drilling of AISI 316 stainless steel. Strojniški vesnik - Journal f Mechanical Engineering, vol. 57, no. 3, p. 165-174, DOI:10.5545/sv-jme.2011.167.

[18] Pušavec, F., Kopač, J. (2011). Sustainability assessment: cryogenic machining of Inconel 718. Strojniški vesnikJournal of Mechanical Engineering, vol. 57, no. 9, p. 637-647, DOI:10.5545/sv-jme.2010.249. 